\title{
LARGE ODONTOGENIC KERATOCYST OF THE MANDIBLE: A COMBINED INTRA/EXTRA ORALAPPROACH FOLLOWED BY ENUCLEATION
}

\author{
Maximilien Vercruysse $^{1 a^{*}}$ (D) ,Patricia D'Haeseleire ${ }^{2 b}$, Sidney Kunz $^{2 b}$, Bart Lutin $^{3 c}$ (D), Constantinus Politis ${ }^{1,4 d}$ (iD \\ 'Department of Oral and Maxillofacial Surgery, University Hospitals Leuven, Leuven, Belgium \\ 2Departments of Oral and Maxillofacial Surgery, AZ Groeninge, Kortrijk, Belgium \\ 3Department of Radiology, AZ Groeninge, Kortrijk, Belgium \\ ${ }^{4}$ Department of Oral and Maxillofacial Surgery, University Hospitals Leuven, Leuven, Belgium; OMFS IMPATH Research Group, Department of Imaging \& \\ Pathology, Faculty of Medicine, University Leuven, Leuven, Belgium
}

${ }^{\mathrm{a} M D}$, Trainee

${ }^{\mathrm{b} M D,}$ DDS

CMD

${ }^{d} M D, D D S, M H A, M M$, PhD, Professor, Head

\begin{tabular}{|c|c|}
\hline DOI: https://doi.org/10. & \\
\hline $\begin{array}{l}\text { enign intraosseus } \\
\text { e rate. In this case } \\
\text { otential treatment } \\
\text { ght mandible near } \\
\text { tra- oral approach. } \\
\text { nandibular access, } \\
\text { eems a reasonable } \\
\text { avoid pathological } \\
\text { cation: Treatment: }\end{array}$ & $\begin{array}{l}\text { Received: June 03, } 2019 \\
\text { Revised: June 13,2019 } \\
\text { Accepted: : une 20, 2019 } \\
\text { Published: June 21, 2019 }\end{array}$ \\
\hline
\end{tabular}

\section{Introduction}

Odontogenic keratocysts (OKC's) of the mandible have been of interest since first presented by Philipsen in $1956[1,17]$. OKC's are considered to be benign intraosseous lesions of odontogenic origin. Evidence suggests that OKC's are to be found posterior to the third molars if offshoots of dental lamina remnants are involved. OKC's occupying the ascending ramus, often present with epithelial island in the mucosa overlying the cyst $[1,2,36]$. The lesions are characterized by a tendency to grow within the medullar space of the mandible/maxilla and have a relatively high recurrence rate. The potential aggressiveness of OKC's is reflected by their potential to extend into soft tissues and bone, although rare. In contrast to ameloblastomas, OKC's cause bone destruction but do not invade through an intact periosteum $[1,33]$. This was questioned by Stoelinga, who cited a few rare instances of keratocysts with soft tissue penetrance $[2,38,43,44,45]$.

OKC's exhibit characteristics of both cysts and benign tumors and were reclassified as odontogenic tumors by the World Health Organization (WHO) in their 2005 Classification of Head and Neck Tumors. In the 2017 classification, the WHO re- categorized the keratocystic odontogenic tumor into the "cyst" category, and the term "odontogenic keratocyst" has been used since. This ambiguity is reflected by their histological characteristics as they present with a cystic architecture but the epithelial lining has a proliferative potential. Histologically the OKC is lined by a regular, keratinized, stratified, squamous epithelium which is 5-10 layers thick and has no rete ridges. The parakeratin surface typically appears corrugated, the basal layer is well defined and frequently palisaded with hyperchromatic nuclei and focal areas showing reversed nuclear polarity. $[3,7,8,41]$. OKC's do not cause metastases or lymph node invasion and do not form tumoral masses. The WHO reclassification could lead to confusion and decreased alertness concerning this lesion. [2,3] When consulting the literature, one must be aware of the different appellations. OKC has a broad age predominance, with a peak incidence in the 2 nd3th decades. In addition, the incidence is higher in male patients, with a male to female ratio of 3:1 [4] Presentation occurs twice as often in the mandible $(70-75 \%)$ as in the maxilla. The posterior body and ascending ramus of the mandible are typical locations. As a consequence, all cysts in the posterior mandibular area have to be treated as if they were OKC's of unicystic ameloblastomas. However, OKC's can also occur in the dentate area of the mandible or maxilla, mimicking ordinary odontogenic cysts. Signs and symptoms can be subtle, but the typical presentation is pain, local swelling, infection and 


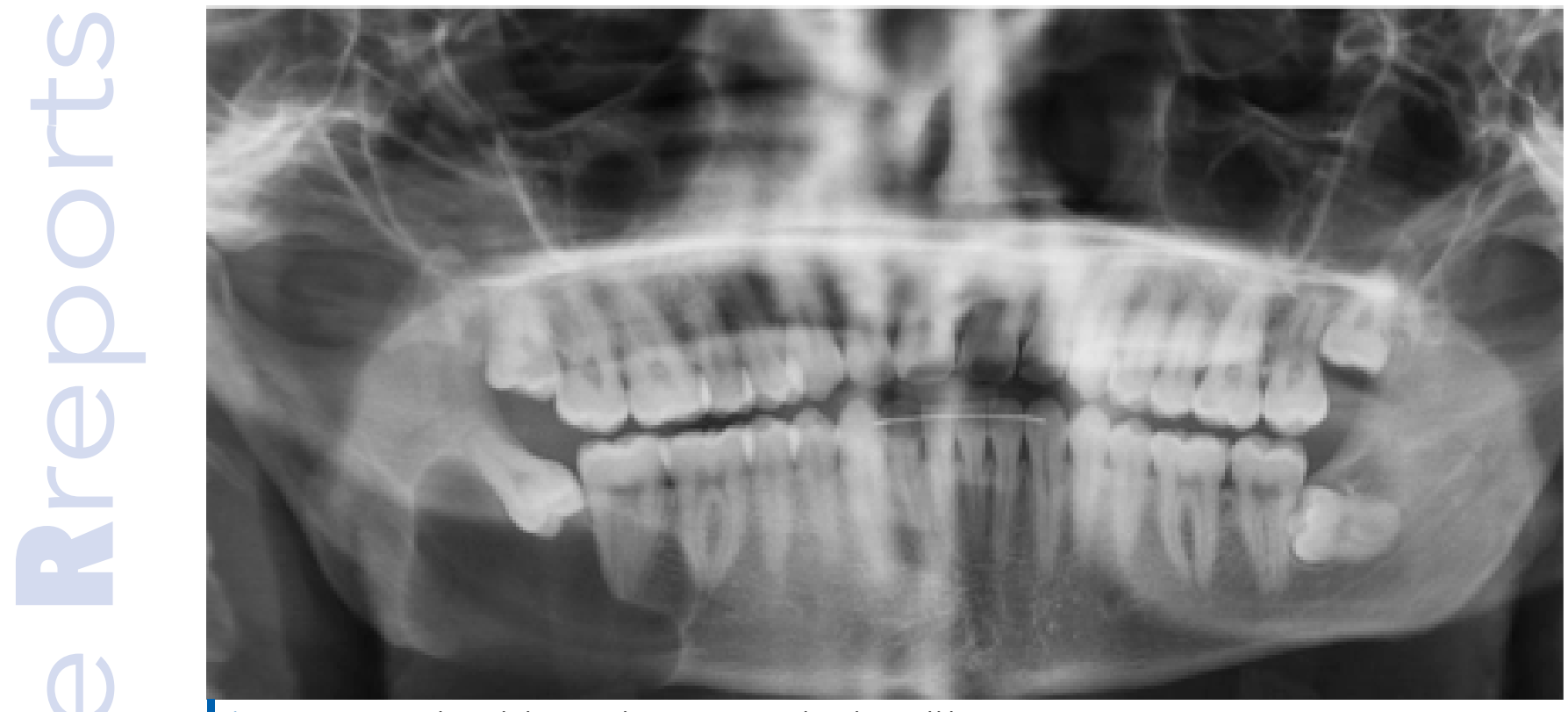

Figure 1. Panoramic radiograph depicting a large cystic mass in the right mandible.

cellulitis $[1,4,6,12,39]$. OKC's are often asymptomatic, probably because they grow in the anteroposterior direction into the intramedullary space, with little cortical expansion. When these lesions reach a large size or perforate the cortical bone, they will often become symptomatic $[9,21,40]$. Of all the cases, 1:3 will be related to an unerupted tooth; the relationship between OKC's and impacted third molars is $10-15 \%$. In addition, growing OKC'scan dislocate away associated teeth [23,24]. OKC's represent approximately $10 \%$ of all cysts of the jaw. They are frequently discovered incidentally by radiographic examination. On radiography, the OKC presents itself as a well-defined radiolucent area. They are commonly unilocular, more rarely multilocular. Often they are not distinguishable from regular odontogenic cysts $[6,9]$. Specific clinical and radiographic characteristics that point to a certain diagnosis pre-operatively are lacking.

The Gorlin Goltz syndrome has to be considered if a patient presents with multiple OKC's. This is an autosomal dominant multisystem disease that leads to multiple OKC's, as well as several nevoid basal cell carcinomas, palmar or plantar pits, calcification of falx cerebri, and skeletal abnormalities. The Gorlin Goltz syndrome is associated with mutations in the PTCH gene situated on $9 q 22.3-q 31$, with described mutation rates of $80-90 \%[1,7,8,16,19,20]$.

The established treatment modalities for OKC's can be divided into radical and conservative treatment options. The radical treatment consists of en bloc resection with negative margins of the segment and has been associated with a recurrence rate of approximately $0 \%$. Knowing the benign nature of this lesion and the morbidity of en bloc resection, this technique has to be reserved for wide, extensive lesions. A retrospective study showed that the main reasons for radical treatment are invasion of the pterygoid muscles and the presence of malignant change $[5,12,13,34]$. The conservative therapies consist of enucleation, but it is generally agreed upon that additional measures for enucleation are crucial to minimize recurrence. The three main techniques are peripheral ostectomy, chemical curettage with application of Carnoy's solution, and cryotherapy. In the literature, there is immense variability in the use of additional techniques, and studies have shown a similar efficacy between peripheral ostectomy and Carnoy's solution. Superior outcomes of cryotherapy have not been described $[6,12,13,21,26]$. Lesions exceeding $3 \mathrm{~cm}$ are not fully suitable for enucleation. In these cases, decompression by marsupialization can reduce the lesion size. The literature has not shown an increased risk of recurrence after decompression [25-27]. It seems advisable to treat each cyst in the mandibular third molar region with possible extension into the ascending ramus by enucleation, with excision of the overlying, attached mucosa if possible. Subsequently, treatment with Carnoy's solution or liquid nitrogen has to be considered. The targeted treatment of the OKC seems achievable, as multiple mutations have been elucidated. Mutations in the PTCH gene or the gene encoding smoothened protein that enhances sonic hedgehog signaling (SMO) can be drug targets. The antimetabolite 5-fluorouracil may affect the sonic hedgehog pathway and has shown lower postoperative morbidity in studies [25,32].

The best treatment for an OKC of the mandible is still a matter of debate, as diagnosis is not straightforward. With this case report, we demonstrate the ambiguity in diagnosis and existing treatment modalities and propose treatment for a large OKC in the right mandible with lingual expansion.

\section{Case presentation}

A 26-year-old Caucasian male was referred to the Department of Oral and Maxillofacial Surgery 

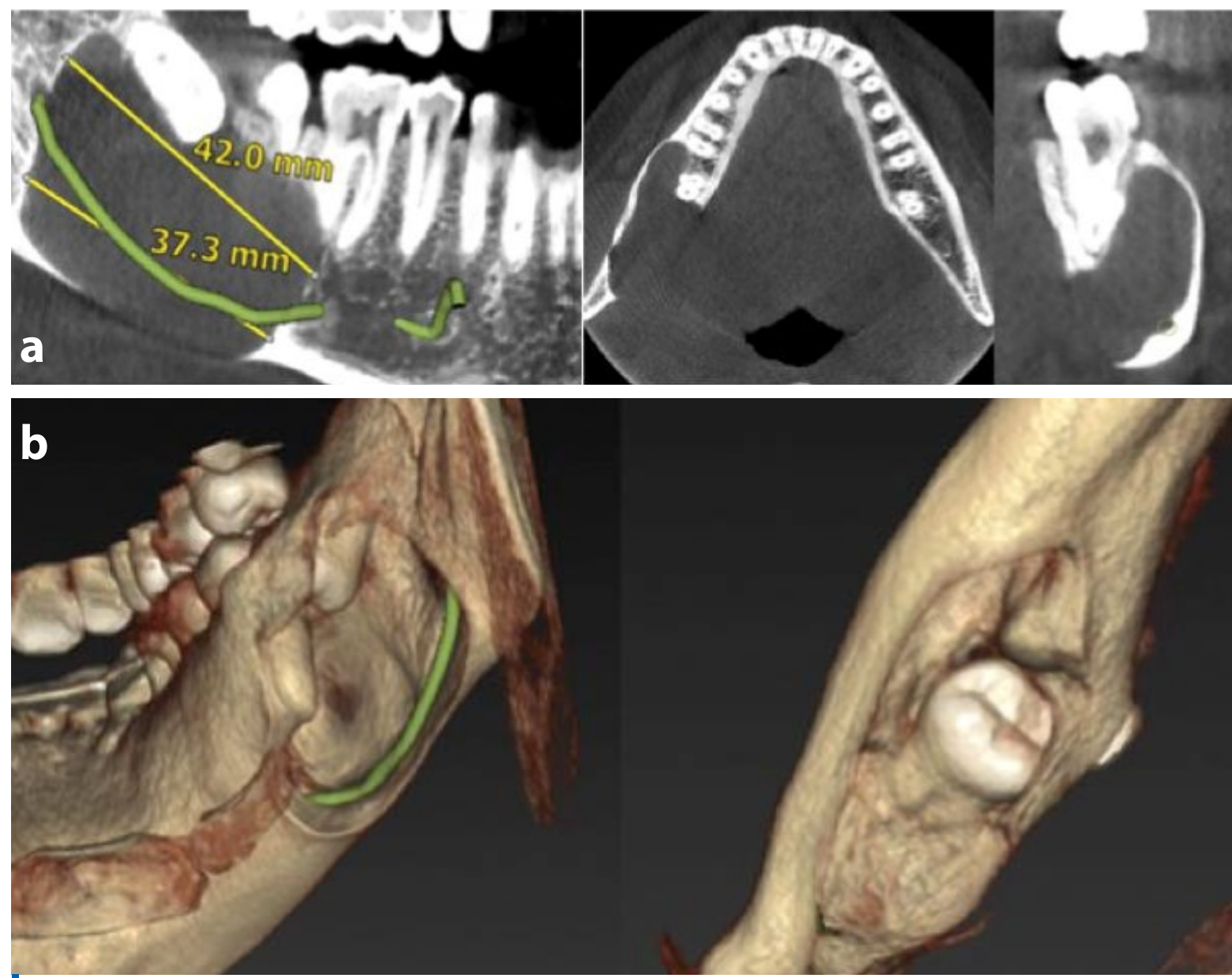

Figure 2. Cone beam computed tomography:

(a) of the right mandible showing a unilocular cystic mass ( $42 \mathrm{~mm} \times 37 \mathrm{~mm}$ )

(b) and 3D volume rendering. The green line indicates the inferior alveolar nerve channel.

complaining of a pain in the right ramus of the mandible, without swelling of this region. Radiographically, there was a unilocular radiolucent lesion with defined borders located in the right mandibular ramus, measuring $42 \mathrm{~mm}$ associated with the retained third molar (Fig. 1). He had no relevant medical history.

Clinical examination did not reveal abnormalities. No regional lymph nodes were palpable and intraoral examination revealed no swelling. Cone beam computed tomography (Fig. 2) showed an expansive, well defined, unilocular cystic lesion longitudinally in the right mandible near the second molar and closely adhering to the third unerupted molar. The lesion had a radiopaque border but caused thinning of the lingual cortex of the mandible with destruction of the cortex at the medial and caudal edge of the mandible. Peri-apical resorption was apparent lateral and posterior to the apex of the second mandibular molar with destruction of the two roots. Neither calcification nor a periosteal reaction wasere identifiable.

On MRI (Fig. 3), were the lesion had homogenous high signal intensity on T2-weighted imaging, low signal intensity on T1-weighted imaging, and homogenous enhancement of the cyst wall after administration of intravenous gadolinium. These characteristics were more suggestive of a benign odontogenic cyst rather than an OKC because of the lack of high intensity on T1-weighted imaging before contrast administration, correlating with ortho/parakeratin or hemorrhage in keratocysts. An ultrasound-guided fine needle biopsy was performed, which was suggestive of an inflammatory follicular or radicular cyst, rather than a keratocyst or ameloblastoma. The surgeons preferred to do a fine needle biopsy instead of an incisional biopsy as it is less invasive and incisional biopsies have the potential for sampling error [42].

A provisional diagnosis of radicular/inflammatory odontogenic cyst was determined. Two weeks later, surgery was performed under general anesthesia. First, a submandibular neck incision $(10 \mathrm{~cm})$ was made, followed by dissection and local excision of the enlarged submandibular lymph nodes. The periosteum was incised over the mandible inferior edge and the mental foramen located. A Martin 2.3 plate was adapted and fixated with 7-9 $\mathrm{mm}$ screws (Fig. 4). The extra oral approach was preferred due to the size of the lesion, the necessity of wide exposure and the fear for a pathological fracture.

Subsequently, teeths 47 and 48 were extracted after preparation of a buccolingual mucoperiosteal flap. Via combined intra/extra-oral access, the cystic mass was exposed. A local posterior gingival resection 


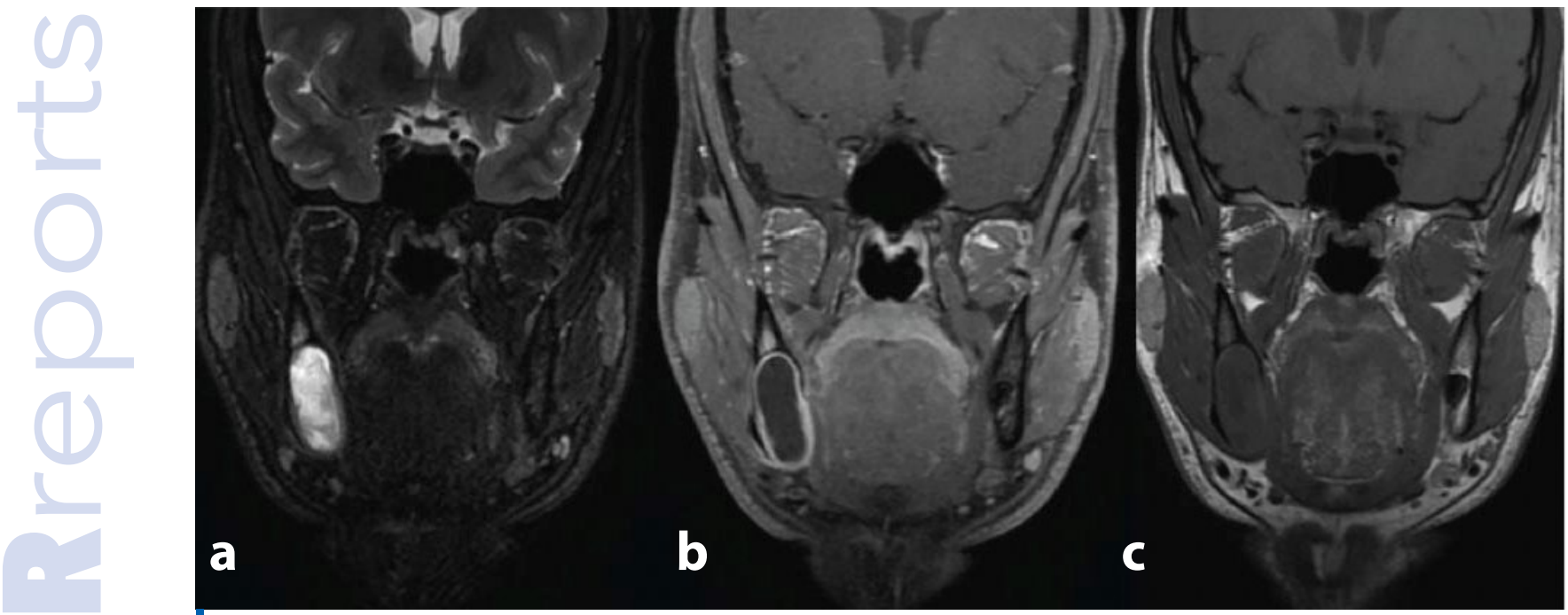

Figure 3. Magnetic resonance imaging:

(a) T2-weighted imaging showing homogenous high signal intensity.

(b) T1-weighted imaging before and

(c) after administration of gadolinium, showing low signal intensity and homogenous enhancement of the cyst wall.

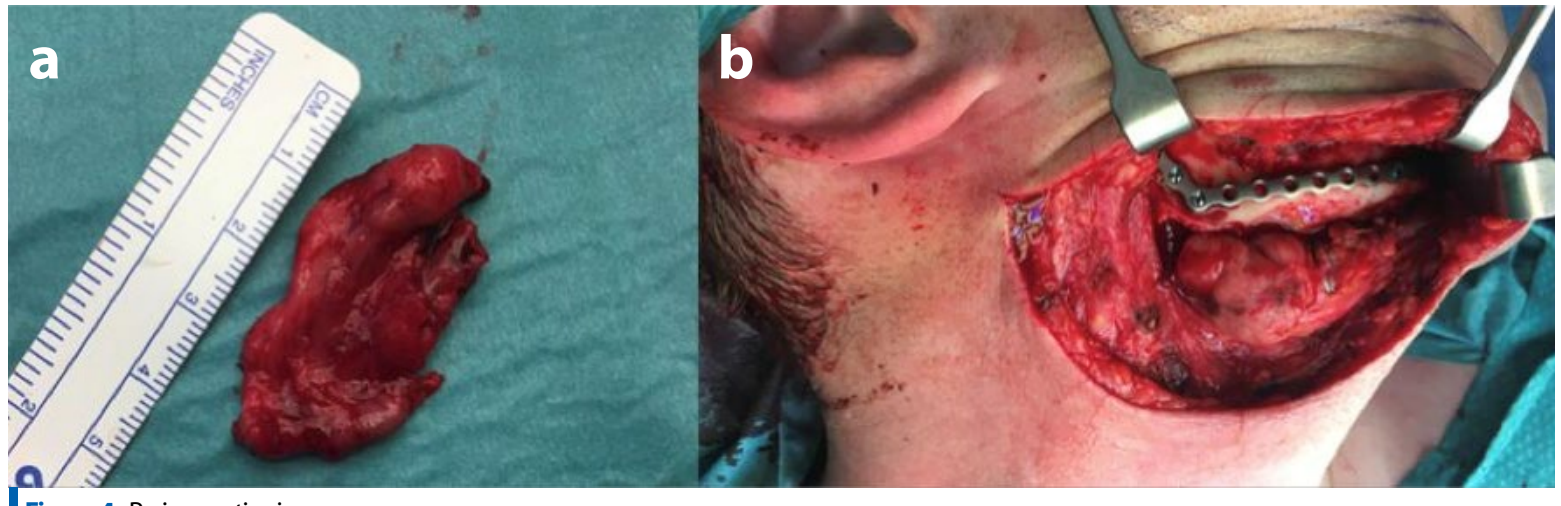

Figure 4. Peri-operative images:

(a) Removed cystic mass and (b) plate osteosynthesis of the right mandible.

was performed by intra-oral access. The inferior alveolar nerve was released of extensive adhesions over $4 \mathrm{~cm}$ without causing a continuity defect. Local bone trepanation was performed to facilitate enucleation while safeguarding bony continuity of the lower border. After flushing, achieving hemostasis, and applying a tetracycline suspension in the intramandibular cavity, intra-oral suturing was performed. The submandibular incision was closed after placing a drain. A postoperative panoramic radiograph showed adequate positioning of the reconstruction plate at the lower border of the right mandible (Fig. 5).

One week after the procedure, the pathology analysis was complete. The microscopic characteristics of the H\&E stained section showed Malpighian epithelium with marked peripheral palisading of the stratum basale. Parakeratosis and orthokeratosis were present with characteristic corrugations of the superficial layer. Some epithelial neutrophilic granulocytes were present and part of the cystic wall was replaced by inflammatory granulation tissue (Fig. 6). Taken together, these findings confirmed the diagnosis of OKC.
Rigorous follow-up was organized with a panoramic radiograph, cephalometric X-ray, and cone beam computed tomography after 6 months, showing no recurrence. The cone beam computed tomography showed a favorable ossifying pattern (Fig. 7). Patient history and clinical examination indicated a favorable healing process (Fig. 8).

\section{Discussion}

The OKC is an expansive, solitary, mostly unilocular (approximately $80 \%$ of cases) jaw lesion thought to arise from remnants of the dental lamina. The active epithelial lining and high proliferation rate reflect a potentially aggressive growth pattern. There is a high recurrence rate, between 25 and $60 \%$, linked to the dental lamina origin and its epithelial islands. Epithelial islands, or micro cysts, can be found in the overlying mucosa in almost $50 \%$ of cases. Research on recurrent OKC's has shown that epithelial islands or micro cysts are present in almost $100 \%$ of recurrent cases [36,37]. The high recurrence rate is attributed to the parakeratotic character of OKC's[8-10]. Most cases of recurrence present within 5 years of treatment, but recurrence after more than 

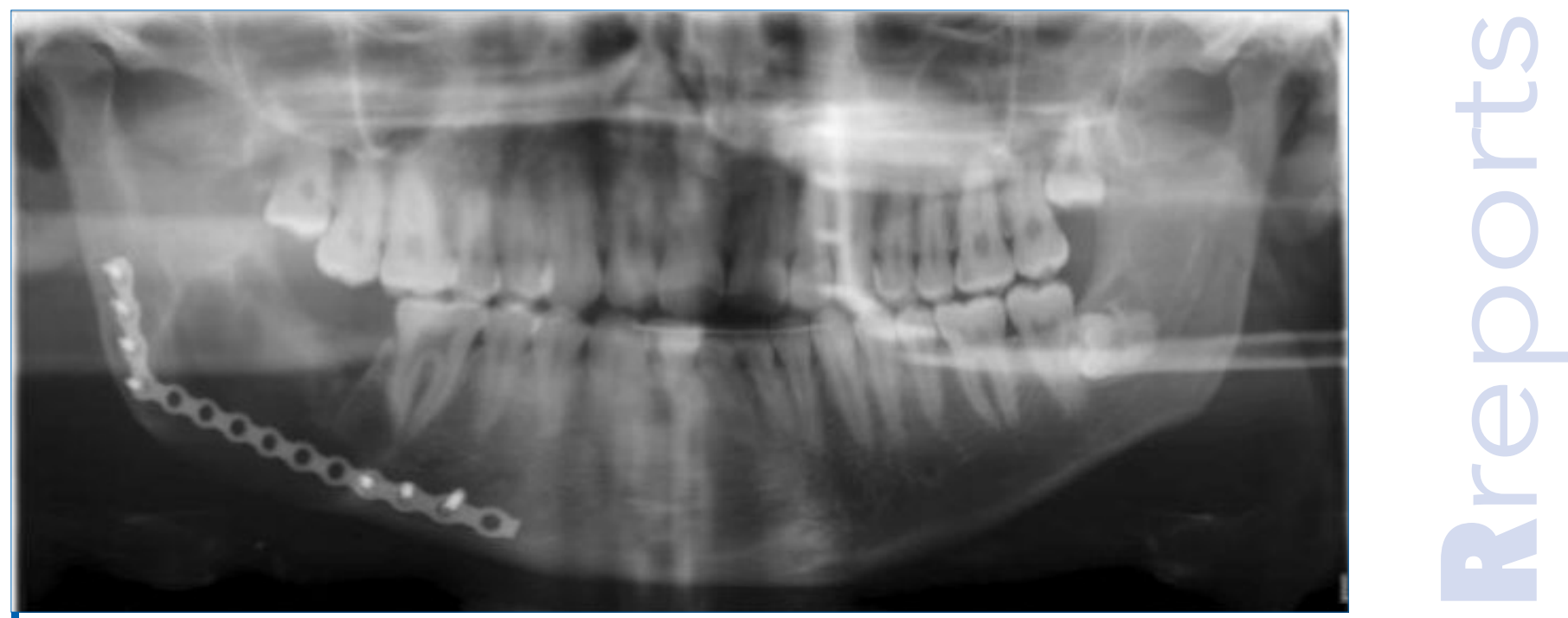

Figure 5. Postoperative panoramic radiograph after removal of the cystic mass and plate osteosynthesis at the lower border of the the right mandible.

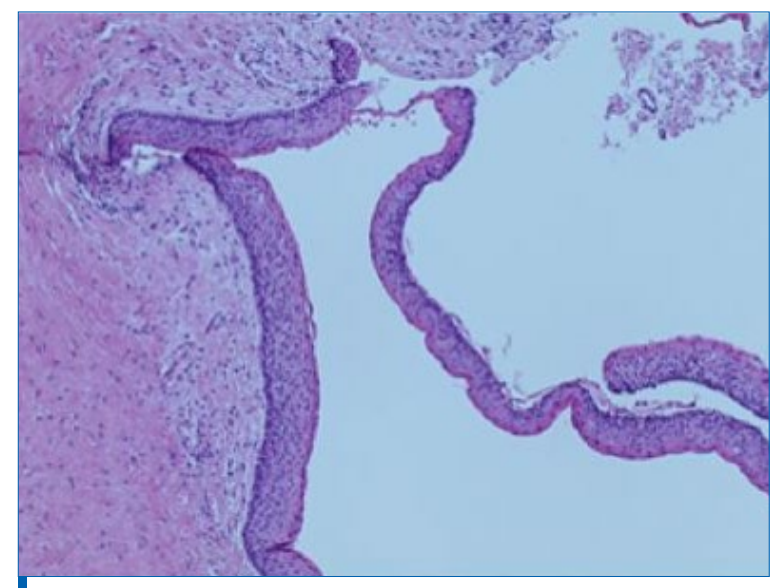

Figure 6. Biopsy of the cystic mandibular mass. Note the wall of the keratocyst with notable palisading and slightly wavy surface.

10 years has been described. Higher recurrence rates have been reported with multilocular lesions and in patients with the Gorlin Goltz syndrome [8$10,14,18,25]$. Our patient consulted with aggravating pain in the right ramus of the mandible and dysgeusia. The dysgeusia was probably caused by a fistula between the lesion and the oral cavity, through which keratin could enter the mouth. Panoramic radiography is helpful in the preliminary assessment, as an OKC will present as a defined radiolucent lesion, mostly unilocular, with smooth and corticated margins [1,3]. Panoramic radiography will show the possible relationship with (impacted) teeth. Cone beam CT should be the next step, as it is considered superior to panoramic radiography because of the possibility to detect bone cortical perforations in the region where the overlying oral mucosa is adhered to the OKC. It is a valuable tool in detecting all dimensions of the lesion with a better identification of the anatomical structures. It has a high spatial resolution but poor contrast resolution, which is not suitable for soft tissue discrimination [1]. Cortical expansion in OKC's will occur more often lingually than buccally. Furthermore, root resorption is rare with $O K C^{\prime}$, in contrast to ameloblastomas, with which root resorption is seen frequently. In our case, the radiolucent lesion caused thinning of the lingual cortex of the mandible and root resorption of the second molar. This highlights that a diagnosis of OKC cannot be made using imaging techniques only. When evaluating a cystic lesion of the mandible, $\mathrm{MRI}$ is a complementary technique to cone beam CT and can be applicable in cases of soft tissue involvement. MRI is superior in illuminating the soft tissue involvement, and a number of studies argue that MRI is crucial in discriminating ameloblastomas from OKC's [28,29]. As such, cone beam CT and $\mathrm{MRI}$, in select cases, are crucial in the diagnosis of OKC's. Some lesions can be indistinguishable from other osteolytic jaw lesions on imaging; therefore, histopathology is always necessary for a definitive diagnosis. A prospective study of 82 OKC's reported that $40 \%$ were not suspected before surgery $[1,22,24]$. The surgeons chose not to execute a preoperative incisional biopsy as it can cause inflammation and interfere in the histopathological analysis of the possurgical specimen.

The differential diagnosis consisted of OKC, ameloblastoma, dentigerous cyst, or radicular cyst. Clinically, these lesions can be indistinguishable, but on imaging they each have typical characteristics. An OKC can be a unilocular or multilocular lesion with few septa and minimal buccolingual expansion. An ameloblastoma typically presents as a multilocular lesion with root resorption and high tendency for buccolingual expansion. A dentigerous cyst will present as a unilocular cyst around the crown of an impacted tooth with possible buccolingual expansion and without septa. Lastly, a radicular/ inflammatory cyst will present as a unilocular lesion connected to the apex of a non-vital tooth [1,24].

Fine needle aspiration biopsy can be considered a safe technique, offering a possibly valuable contribution to pre-operative diagnosis. However, it can be misleading due to inflammation in OKC's. 

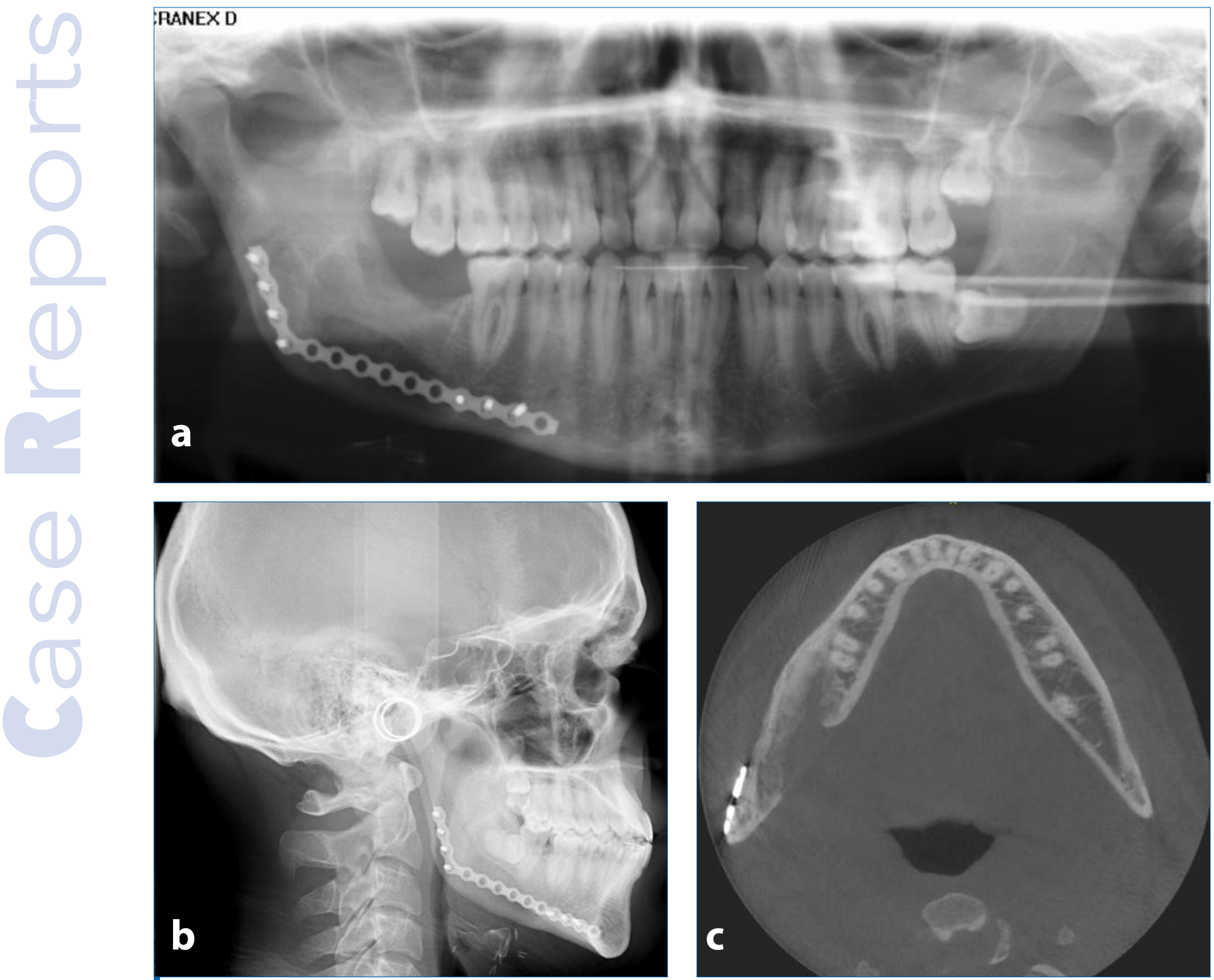

Figure 7. Follow-up 6 months after surgery: (a) Panoramic radiograph, (b) cephalometric X-ray, and (c) cone beam computed tomography.

In addition, a biopsy of an unrepresentative area of the lesion can be misleading. The result can be indicative, but a negative result can never rule out a possible diagnosis of OKC until investigation of the final resection specimen. Baykul et al. showed a correlation of $89.95 \%$ between cytological and histopathological diagnosis for cystic lesions in the maxillofacial region [22,29,30,31].

With this in mind, diagnosis and subsequent treatment of OKC's poses a challenge. The objective is to reduce the recurrence risk as much as possible, while minimizing morbidity. This delicate balance has led to heavy international debate, and no consensus on treatment has been reached.

Conventional treatment modes were described in this article, however, for this specific case an adapted treatment was performed. Because of the size of the lesion and its lingual expansion, there was uncertainty about mandibular stability after enucleation. The location of the lesion with immediate connection to the deep neck soft tissues could not be neglected. The expanded resorption of the lingual cortex with broad fenestration could induce a pathological fracture after enucleation with bone trepanation for removal of teeths 47 and 48 . Therefore, a combined intra/extra-oral technique was applied.

By adapting and fixating a plate before performing the enucleation, we tried to avoid a pathological fracture. With this degree of extended osteolysis, we felt fixation of a plate was necessary. What if mandibular continuity resection is necessary perioperatively? Then, the mandibular bony contour would be guaranteed by using the reconstruction plate. As no clear arguments for OKC were present pre-operatively and peri-operatively, the surgeons decided not to use Carnoy's solution because of the location of the inferior alveolar nerve and the potential neurotoxicity, saving soft tissue as much as possible.

The described technique seems suitable for lesions of this size when pathological fractures are likely. It provides an elegant way to provide mandibular continuity while executing enucleation. We are aware that the short follow-up is a limitation of this case report. 


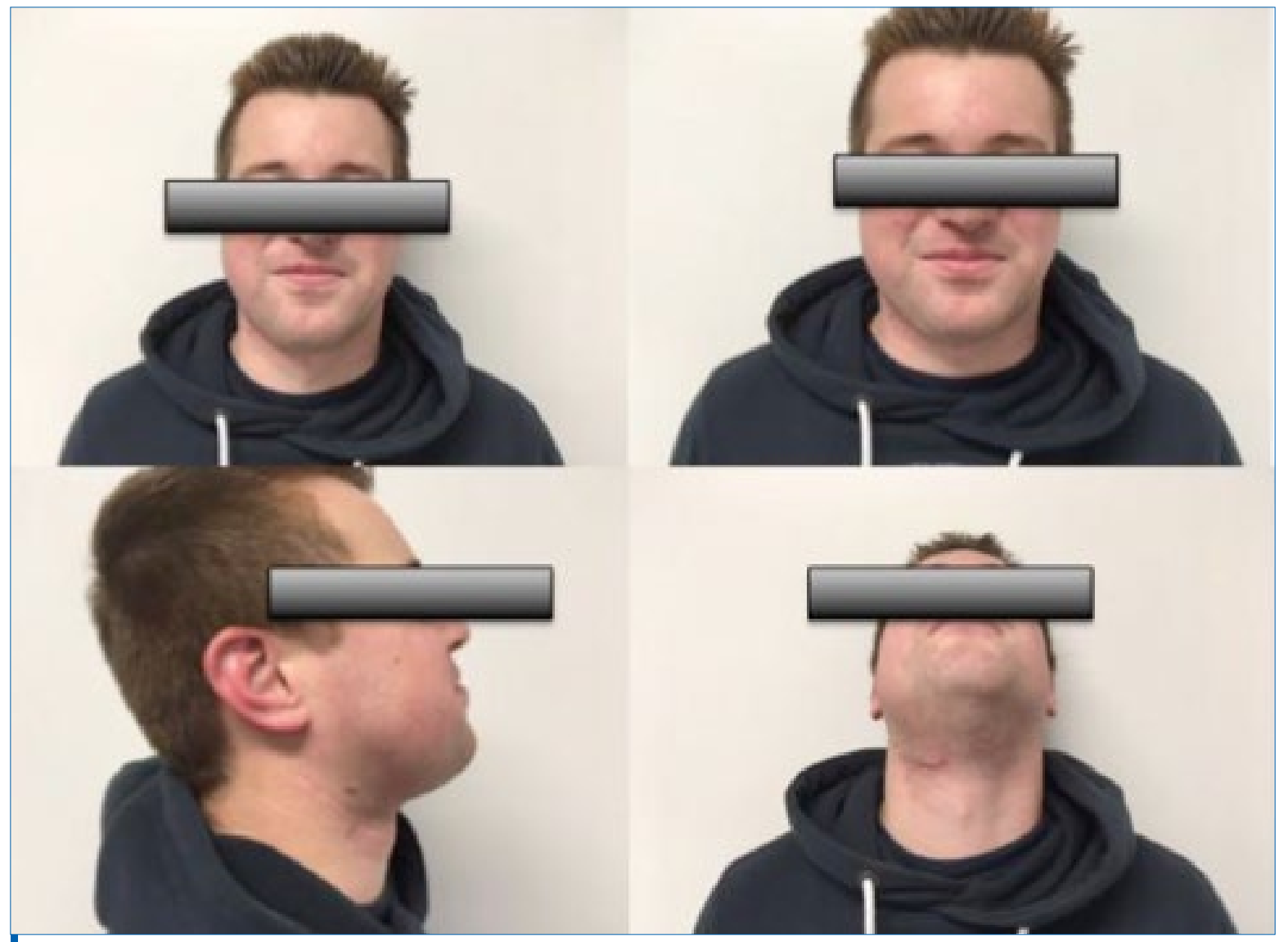

Figure 8. Clinical pictures 6 months after surgery

\section{Conclusion}

With this case report, we tried to point out the difficult diagnosis of OKC and, by extension, all radiolucent lesions of the mandible. Although the lesion does not always present with its typical features, the possibility of OKC must be taken into account when setting up a treatment protocol.

Given the presented case, the combined intra/ extra oral approach is a reasonable technique for the treatment of similar OKC's in order to avoid pathological fractures as well as guaranteeing total removal of the lesion.

\section{Conflicts of interest}

None

\section{Funding}

This research did not receive any specific grant from funding agencies in the public, commercial, or notfor-profit sectors.

\section{Ethical approval}

Not applicable. The present study is not a research study.

\section{Consent}

Written informed consent was obtained from the patient for the publication of this case report and the accompanying images.

\section{Author Contributions}

MV: leading author of the manuscript. PD: critically revising the manuscript. SK: critically revising the manuscript. BL: giving more insight in radiologic aspect of the case report. CP: critically revising the manuscript.

\section{Acknowledgments}

The authors would like to thank all those who were involved in the construction of this article. 


\section{References}

1. Borghesi A, Nardi C, Giannitto C, et al. Odontogenic keratocyst: imaging features of a benign lesion with an aggressive behavior Insights into Imaging. 2018;9(5):883-897.

[Full text links] [Free PMC Article] [CrossRef] [PubMed] Google Scholar

2. Stoelinga PJW. Keratocystic odontogenic tumor (KCOT) has again been renamed odontogenic

keratocyst (OKC). Int J Oral Maxillofac Surg. 2019;48(3):415-416.

[Full text links] [CrossRef] [PubMed] Google Scholar

3. Wright J, Vered M. Update from the 4th Edition of the World Health Organization classification

of head and neck tumors: odontogenic and maxillofacial bone tumors. Head Neck Pathol. 2017;11(1):68-77.

[Full text links] [CrossRef] [PubMed] Google Scholar Scopus

4. De Castro M, Caixeta $C$, de Carli M, et al. Conservative surgical treatments for nonsyndromic odontogenic keratocysts: A systematic review and meta-analysis. Clin Oral Investig. 2017;22(5):2089-2101.

[Full text links] [CrossRef] [PubMed] Google Scholar Scopus

5.ScarfeW, Toghyani S, Azevedo B. Imaging of benign odontogenic lesions. Radiol Clin North Am. 2018;56(1):45-62

[Full text links] [CrossRef] [PubMed]

6. De Molon R, Verzola M, Pires $L$, et al. Five years follow-up of a keratocyst odontogenic tumor treated by marsupialization and enucleation: A case report and literature review. Contemp Clin Dent. 2015; 6(Suppl 1):S106-S110.

[Full text links] [Free PMC Article] [CrossRef] [PubMed] Google Scholar

7. Kamil A, Tarakji B. Odontogenic keratocyst in children: A review. Open Dent J. 2016;10(1):117-123.

[Full text links] [CrossRef] [PubMed] Scopus

8. Pittl T, Meier M, Hakl $\mathrm{P}$, et al. Long-term observation of a large keratocystic odontogenic tumor of the mandible treated by a single enucleation procedure: A case report and literature review. Int J Surg Case Rep. 2017;34:119-122.

[Full text links] [CrossRef] [PubMed] Google Scholar

9. Kebede B, Dejene D, Teka A, et al. Big keratocystic odontogenic tumor of the mandible: A case report. Ethiop J Health Sci. 2016;26(5):491-496.

[Full text links] [PubMed] Google Scholar Scopus

10. Gnanaselvi UP, Kamatchi D, Sekar K, Narayanan BS. Odontogenic keratocyst in anterior mandible:

An interesting case report. J Contemp Dent Pract. 2016;3(1):22-24. [CrossRef] [PubMed] Google Scholar

11. Kurien N, Kumar L, Uma $P$, et al. An extensive swelling in the anterior mandible - A case report.

Ann Med Surg (Lond). 2017;21:30-33.

[Full text links] [CrossRef] [PubMed] Google Scholar Scopus

12. Mosier KM. Keratocystic odontogenic tumor. STATdx [Internet].

2018 [cited 2018 Jan 10].Available from: https://app.statdx com/document/ameloblastoma/53cf7bc7-2f8f-4fdc-8112 519cb50ce74c

13. Mukherjee D, Pati A. Odontogenic keratocyst involving mandible-A Case Report. Int J Adv Res. 2018;6(6):635-641. [CrossRef]

14. Karandikar S, Nilesh K, Dadhich A. Large odontogenic keratocyst of mandible- A case report. JIDA. 2011;5(7):822-824

15. Rajkumar G, Hemalatha M, Shashikala R, Sonal P. Massive keratocystic odontogenic tumor of mandible: A case report and review of literature. Indian J Dent Res. 2011;22(1):181.

[Full text links] [CrossRef] [PubMed] Google Scholar Scopus

16. García de Marcos J, Dean-Ferrer A, Arroyo Rodríguez S, et al.

Basal cell nevus syndrome: clinical and genetic diagnosis. Oral Maxillofac Surg. 2009;13(4):225-230.

[Full text links] [PubMed] Google Scholar Scopus

17. Pogrel MA. The history of the odontogenic keratocyst. Oral Maxillofac Surg Clin North Am. 2003;15(3):311-315.

[CrossRef] [PubMed] Scopus

18. Bell RB, Dierks EJ. Treatment options for the recurrent odontogenic keratocyst. Oral Maxillofac Surg Clin North Am. 2003;15(3):429-446.

[Full text links] [CrossRef] [PubMed] Google Scholar Scopus

19. Li TJ. The odontogenic keratocyst. J Dent Res. 2011;90(2):133-142.

20. Gosau M, Draenert F, Müller S, et al. Two modifications in the treatment of keratocystic odontogenic tumors (KCOT) and the use of Carnoy's solution (CS)--a retrospective study lasting between 2 and 10 years. Clin Oral Investig. 2009;14(1):27-34.

[Full text links] [CrossRef] [PubMed] Google Scholar

21. Menon S. Keratocystic odontogenic tumors: Etiology, pathogenesis and treatment revisited. J Maxillofac Oral Surg. 2014;14(3):541-547.

[Full text links] [CrossRef] [PubMed] Google Scholar

22. Chapelle K, Stoelinga P, de Wilde P, et al. Rational approach to diagnosis and treatment of ameloblastomas and odontogenic keratocysts. Br J Oral Maxillofac Surg. 2004;42(5):381-390. [Full text links] [CrossRef] [PubMed] Google Scholar Scopus 23. Pogrel M. The keratocystic odontogenic tumour (KCOT)-an odyssey. Int J Oral Maxillofac Surg. 2015:44(12):1565-1568. [Full text links] [CrossRef] [PubMed] Google Scholar 24. Vigneswaran AT, Shilpa S. The incidence of cysts and tumors associated with impacted third molars. J Pharm Bioallied Sci. 2015; 7(Suppl 1): S251-S254.

[Full text links] [Free PMC Article] [CrossRef] [PubMed] Google Scholar Scopus

25. Peacock Z. Controversies in Oral and Maxillofacial Pathology. Oral Maxillofac Surg Clin North Am. 2017;29(4):475-486.

[Full text links] [CrossRef] [PubMed] Google Scholar Scopus

26. Ribeiro-Júnior $O$, Borba $A$, Alves $C$, et al. Reclassification and treatment of odontogenic keratocysts: A cohort study. Braz Oral Res. 2017;31:e98.

[Full text links] [CrossRef] [PubMed] Google Scholar Scopus

27. Cakarer S, Isler S, Keskin B, et al. Treatment for the large aggressive benign lesions of the jaws. J Maxillofac Oral Surg. 2017;17(3):372-378

CrossRef] [PubMed] Google Scholar

28. Hisatomi M, Asaumi J, Konouchi $\mathrm{H}$, et al. MR imaging of epithelial cysts of the oral and maxillofacial region. Eur J Radiol 2003;48(2):178-182.

[Full text links] [CrossRef] [PubMed] Google Scholar

29. Vargas P, da Cruz Perez D, Mata G, et al. Fine needle aspiration cytology as an additional tool in the diagnosis of odontogenic keratocyst. Cytopathology. 2007;18(6):361-366.

[Full text links] [CrossRef] [PubMed] Google Scholar Scopus 30. Goyal S, Sharma S, Kotru M, Gupta N. Role of FNAC in the diagnosis of intraosseous jaw lesions. Med Oral Patol Oral Cir Bucal. 2015;20(3):e284-e291.

[Full text links] [CrossRef] [PubMed] Google Scholar Scopus

31. Timucin Baykul O. The value of aspiration cytology in cystic lesions of the maxillofacial region [Internet]. PubMed Central (PMC). 2018 [cited 2018 Dec 19]. Available from: https://www. ncbi.nlm.nih.gov/pmc/articles/PMC2798782/

32. Ledderhof $N$, Caminiti M, Bradley G, Lam D. Topical 5 -fluorouracil is a novel targeted therapy for the keratocystic odontogenic tumor. J Oral Maxillofac Surg. 2017;75(3):514-524.

[Full text links] [CrossRef] [PubMed] Google Scholar Scopus

33. Shear $M$. The aggressive nature of the odontogenic keratocyst: is it a benign cystic neoplasm? Part 1. Clinical and early experimental evidence of aggressive behavior. Oral Oncol. 2002;38(3):219-226.

[Full text links] [CrossRef] [PubMed] Google Scholar

34. Warburton G, Shihabi A, Ord R. Keratocystic odontogenic tumor (KCOT/OKC)-Clinical guidelines for resection. J Maxillofac Oral Surg. 2015;14(3):558-564.

[Full text links] [CrossRef] [PubMed] Google Scholar

35. Stoelinga P. The management of aggressive cysts of the jaws. $J$ Maxillofac Oral Surg. 2012;11(1):2-12

[Full text links] [CrossRef] [PubMed] Google Scholar 36. Stoelinga PJW. Keratocystic odontogenic tumour (KCOT) has again been renamed odontogenic keratocyst (OKC). Int J Oral Maxillofac Surg. 2019:48(3):415-416.

[Full text links] [CrossRef] [PubMed] Google Scholar

37. Stoelinga PJ. The treatment of odontogenic keratocysts by excision of the overlying, attached mucosa, enucleation, and treatment of the bony defect with Carnoy solution. J Oral Maxillofac Surg. 2005;63(11):1662-1666.

[Full text links] [CrossRef] [PubMed] Google Scholar Scopus

38. Stoelinga PJ. Long-term follow-up on keratocysts treated according to a defined protocol. J Oral Maxillofac Surg. 2001;30(1):14-25.

[Full text links] [CrossRef] [PubMed] Google Scholar Scopus

39. Slusarenko da Silva $Y$, Stoelinga $P$, Naclério-Homem $M$. The presentation of odontogenic keratocysts in the jaws with an emphasis on the tooth-bearing area: a systematic review and meta-analysis. Oral Maxillofac Surg. 2019;23(2):133-147.

[Full text links] [CrossRef] [PubMed] Google Scholar Scopus

40. Slusarenko da Silva Y, Naclério-Homem MG. Conservative treatment of primary and nonsyndromic odontogenic keratocyst: an overview of the practice. Int J Oral Dent Health. 2018;4(2):1-6. Google Scholar

41. Shear M, Speight PM. Cysts of the oral and maxillofacial regions. 4th Edition. Oxford, UK: Blackwell Publishing Ltd; 2007. Google Scholar

42. Padilla $R$, Murrah V. The potential for sampling error in incisional biopsies of odontogenic keratocysts. Oral Surg Oral Med Oral Pathol Oral Radiol Endod. 2004;98(2):202.

Google Scholar 
43. Worrall S. Recurrent odontogenic keratocyst within the temporalis muscle. Br J Oral Maxillofac Surg. 1992;30(1):59-62.

[PubMed] Google Scholar Scopus

44. Abé T, Maruyama S, Yamazaki M, et al. Intramuscular keratocyst

as a soft tissue counterpart of keratocystic odontogenic tumor:

differential diagnosis by immunohistochemistry. Hum Pathol.

2014;45(1):110-118.

[Full text links] [CrossRef] [PubMed] Google Scholar Scopus
45. Makarla S, Bavle R, Muniswamappa S, Narasimhamurthy S. A Large extragnathic keratocystic odontogenic tumour. Case Rep Pathol. 2015;2015:1-7.

[Full text links] [CrossRef] [PubMed] [PMC] Google Scholar

Maximilien VERCRUYSSE

MD, Trainee

Department of Oral and Maxillofacial Surgery

University Hospitals Leuven Leuven, Belgium

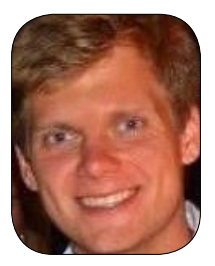

Maximilien Vercruysse is a trainee at the Department of Oral and Maxillofacial Surgery, University Hospitals Leuven, Leuven, Belgium.

\section{Questions}

1. What percentage of the cases present the odontogenic keratocyst in the mandible (approximately)?

ㅁ. $10 \%$;

ab. $20 \%$;

ac. $40 \%$;

ad. $70 \%$.

2. Which syndrome is strongly associated with a higher rate of OKC's?

Da. Pierre robin syndrome;

ab. Gorlin Goltz syndrome;

Dc. Neurofibromatosis;

ad. Treacher Collins Syndrome.

3. Recurrence rate after $\mathbf{5}$ year follow up of a surgically treated non-syndromal keratocyst is approximately?

Da. $0-5 \%$;

ab. $0-20 \%$;

ac. $20-40 \%$;

ad. $60-80 \%$.

\section{Male to female ratio of OKC's can be estimated at?}

ㅁ. 3:1;

ab. 1:1;

口c. 1:2;

ad. 1:3. 